\title{
Strategi Komunikasi Program Radio Pendidikan Sebagai Media Sumber Pembelajaran dan Informasi
}

\author{
Syifa Nurhaliza ${ }^{1}$, Farid Rusdi ${ }^{*}$ \\ ${ }^{1}$ Fakultas Ilmu Komunikasi, Universitas Tarumanagara, Jakarta \\ Email: syifa.nurhaliza99@gmail.com \\ ${ }^{2}$ Fakultas Ilmu Komunikasi, Universitas Tarumanagara, Jakarta* \\ Email: farid@fikom.untar.ac.id
}

Masuk tanggal: 15-12-2021, revisi tanggal: 06-01-2022, diterima untuk diterbitkan tanggal:16-01-2022

\begin{abstract}
Suara Edukasi AM is an educational radio broadcast that has been organized by the Center for Data and Information Technology of the Ministry of Education and Culture. Radio requires a special communication strategy so that the information broadcast every day can be received and easily accepted by listeners and provides benefits to the listeners, especially in the Covid19 pandemic situation. In the midst of many radio stations that are no longer active due to the existence of radio nowadays, many have been replaced by other, more modern mass media, but Suara Edukasi radio remains consistent and provides a lot of information about education and other entertainment. The purpose of the study was to identify and describe the planning, evaluation, management and challenges faced by Suara Edukasi radio in managing and providing information during the Covid-19 pandemic. In addition, it is also to describe the communication strategy carried out by Suara Edukasi educational radio in providing learning information, in order to retain and attract listeners in the midst of the Covid-19 pandemic through its broadcast program. This study will describe the stages of communication strategy described by Phil Jones. With a qualitative method research approach, the authors collect primary data with interviews and field observations. Then secondary data was obtained through websites, articles, and books. As a result, there are several challenges that must be faced by Suara Edukasi radio, but the radio can carry out the stages of communication strategy well, in order to achieve an organizational goal. At this time, communication strategies during the pandemic that have been defined and refined will continue to be used and developed.
\end{abstract}

Keywords: communication strategy, Covid-19, educational radio

\begin{abstract}
Abstrak
Suara Edukasi AM adalah siaran radio pendidikan yang telah diselenggarakan oleh Pusat Data dan Teknologi Informasi Kementerian Pendidikan dan Kebudayaan. Radio membutuhkan strategi komunikasi khusus agar informasi yang disiarkan setiap harinya dapat diterima dan mudah diterima oleh pendengar dan memberi manfaat kepada para pendengarnya terutama dalam situasi pandemi Covid-19. Ditengah banyaknya stasiun radio yang sudah tidak aktif dikarenakan eksistensi radio pada masa sekarang sudah banyak tergantikan oleh media massa lainnya yang lebih modern, namun radio Suara Edukasi tetap konsisten dan tetap memberikan banyak informasi seputar pendidikan maupun hiburan lainnya. Tujuan dari penelitian adalah untuk mengetahui dan mendeskripsikan dari mulai proses perencanaan, evaluasi, pengelolaan dan tantangan yang dihadapi oleh radio Suara Edukasi dalam mengelola dan memberikan informasi pada masa pandemi Covid-19. Selain itu juga untuk mendeskripsikan strategi komunikasi yang dilakukan radio pendidikan Suara Edukasi dalam memberikan informasi pembelajaran, agar dapat mempertahankan dan menarik pendengar ditengah pandemi Covid19 melalui program siarannya. Penelitian ini akan memaparkan tahapan strategi komunikasi
\end{abstract}


yang dipaparkan oleh Phill Jones. Dengan pendekatan penelitian metode kualitatif, penulis mengumpulkan data primer dengan wawancara dan observasi dilapangan. Kemudian data sekunder diperoleh melalui website, artikel, dan buku. Hasilnya, ada beberapa tantangan yang harus dihadapi oleh radio Suara Edukasi, namun radio tersebut dapat melakukan tahapantahapan strategi komunikasi dengan baik, demi tercapainya sebuah tujuan organisasi. Pada saat ini, strategi komunikasi selama pandemi yang sudah ditetapkan dan disempurnakan akan terus digunakan dan dikembangkan.

Kata Kunci: Covid-19, radio pendidikan, strategi komunikasi

\section{Pendahuluan}

Pandemi Covid-19 di Indonesia, memberikan dampak besar pada berbagai sektor kehidupan seperti ekonomi, sosial, budaya dan kesehatan, bahkan pada sektor pendidikan. Situasi pandemi mengharuskan pemerintah untuk menerapkan kebijakan work from home (WFH), agar masyarakat dapat beraktivitas dari rumah masingmasing. Dari sisi pandangan pendidikan, siswa diharuskan untuk belajar dari rumah. Dilansir dari laman Databoks.katadata.co.id bahwa 78\% sekolah di Indonesia, masih menerapkan sistem pembelajaran jarak jauh. Data tersebut bersumber dari Kementrian Pendidikan dan Kebudayaan pada tanggal 30 Maret 2021. Suara Edukasi AM adalah siaran radio pendidikan yang diselenggarakan Pusat Data dan Teknologi Informasi Kementerian Pendidikan dan Kebudayaan, untuk menjadi siaran radio yang dapat digunakan sebagai media alternatif sumber belajar, dalam rangka mencapai tujuan pendidikan Nasional.

Radio adalah salah satu jenis media massa elektronik yang tertua, dan sampai saat ini masih menjadi pilihan karena radio mengandung unsur musik, kata-kata, dan juga memiliki jangkauan paling luas karena kemampuannya menembus jarak dan waktu (Dominica et al., 2021). Eksistensi radio mulai mengalami penurunan akibat semakin banyaknya media yang lebih menarik seperti televisi, media online dan media lainnya. Hal tersebut menjadi tugas berat bagi pengelola radio untuk berusaha mempertahankan pendengar mereka sehingga tidak ditinggalkan begitu saja. Pada saat ini masih ada beberapa radio yang bertahan karena kemampuannya dalam beradaptasi dengan teknologi digital. Selain pendengar yang menyimak pesan dari gelombang elektromagnetik, kini hadir pendengar yang menyimak pesan melalui ponsel pintar mereka (Amiliani et al., 2020). Radio membutuhkan strategi komunikasi khusus, agar informasi yang disiarkan setiap harinya dapat diterima dan mudah dipahami oleh pendengar, serta bisa memberi manfaat kepada para pendengarnya.

Strategi komunikasi adalah suatu panduan perencanaan komunikasi dengan manajemen komunikasi untuk mencapai tujuan yang ditetapkan (Effendy \& Surjaman, 2011). Salah satu fungsi strategi komunikasi adalah menyebarluaskan pesan komunikasi yang bersifat informatif, persuasif, dan juga instruktif secara sistematik tepat sasaran untuk memperoleh hasil yang optimal (Effendy, 2003).

Strategi komunikasi ini penting untuk dilakukan, mengingat hingga saat ini masih banyak para pelajar serta tenaga pengajar atau guru yang masih melakukan aktivitas pembelajaran dari rumah dan mengajar dari rumah. Sehingga hal tersebut dapat menjadi peluang, untuk radio khususnya Suara Edukasi, agar pendengarnya semakin bertambah. Karena disaat pandemi seperti ini intensitas masyarakat untuk menyimak sebuah media semakin meningkat, serta kebutuhan informasi juga meningkat. Strategi komunikasi memiliki tiga tujuan utama, yaitu untuk 
mengamankan pemahaman, untuk menetapkan penerimaan dan juga untuk memotivasi tindakan (Effendy, 2003).

Dalam mencapai tujuan tersebut dibutuhkan berbagai tahapan strategi komunikasi yang efektif. Setiap tahap proses awal sampai akhir itu sangat penting karena proses tersebut akan mempengaruhi hasil akhirnya. Oleh karena itu organisasi harus memperhatikan proses demi proses atau tahapan. Teori tahapan strategi komunikasi yang dipaparkan oleh Phill Jones, dapat dilakukan oleh organisasi untuk mencapai sebuah tujuannya yaitu, (1) Analisis dan Perencanaan Strategis; (2) Desain Strategi dan Implementasi Perencanaan; (3) Pelaksanaan Strategi; (4) Tindak Lanjut dan Komitmen; (5) Menambahkan Strategi dan Pelacakan Hasil (Phil Jones, 2012). Tahapan strategi komunikasi tersebut dilakukan oleh radio Suara Edukasi dalam mencapai sebuah tujuannya pada masa pandemi Covid-19, mulai dari proses perencanaan, pengelolaan, evaluasi, dan tantangan yang dihadapi oleh radio Suara Edukasi dalam mengelola dan memberikan informasi pada masa pandemi Covid-19. Selain itu juga dalam memberikan informasi pembelajaran, agar dapat mempertahankan dan menarik pendengar ditengah pandemi Covid-19 melalui program siarannya.

Definisi dari program siaran yaitu, satu bagian atau segmen dari isi siaran radio atau televisi secara keseluruhan. Sehingga dalam siaran keseluruhan terdapat beberapa program atau acara yang diudarakan, setiap program mempunyai slot waktu tertentu sesuai dengan durasi jenis programnya, contohnya seperti program jenis hiburan , berita dan informasi edukasi (Djamal et al., 2017). Dari gambaran yang telah dipaparkan, maka fokus masalah dari penelitian ini adalah untuk mengetahui dan mendeskripsikan bagaimana proses perencanaan, evaluasi, pengelolaan dan mengetahui bagaimana strategi komunikasi yang dilakukan radio Suara Edukasi AM dalam mempertahankan dan menarik pendengarnya pada saat pandemi Covid-19, dengan menggunakan teori tahapan strategi Phill Jones.

\section{Metode Penelitian}

Dalam penelitian ini menggunakan pendekatan konstruktivis dan jenis penelitian yang digunakan adalah deskriptif kualitatif. Selain itu metode yang digunakan dalam penelitian ini adalah studi kasus yang berfokus pada pengembangan deskripsi yang mendalam dan juga menganalisa suatu kasus atau fenomena (Creswell, 2013), untuk menyelesaikan masalah dan mendapatkan perkembangan dari masalah tersebut. Dalam metode pengumpulan data dalam penelitian ini, peneliti mengumpulkan data dengan tiga cara yaitu, wawancara mendalam dengan tiga narasumber dari radio Suara Edukasi, observasi dan dokumentasi.

Dalam penelitian ini subjek penelitiannya adalah radio Suara Edukasi, objek penelitian ini adalah sifat keadaan dari suatu benda dan orang atau individu yang menjadi pusat perhatian dan juga sasaran penelitian. Sifat keadaan yang dimaksud adalah kuantitas dan kualitas yang dapat berupa perilaku, pendapat, pandangan, kegaiatan, dan dapat juga berupa sebuah proses. Objek dari penelitian ini adalah strategi komunikasi program radio pendidikan sebagai media sumber pembelajaran dan informasi (studi di radio Suara Edukasi AM di tengah pandemi Covid-19).

Adapun juga sumber data primer yang digunakan dalam penelitian kualitatif ini adalah Informan yaitu, orang yang diwawancarai. Informan kunci yang relevan dalam penelitian ini yaitu, dengan cara purposive sampling atau dengan cara sengaja. Pemilihan informan dengan teknik purposive sampling menghasilkan, Sub 
Koordinator Produksi Bahan Belajar Pusdatin Kemdikbudristek bagian dari pengkaji media naskah radio/audio sebagai informan kunci yang mengetahui secara keseluruhan tentang radio Suara Edukasi ini. Kemudian teknik berikutnya yang dipakai dalam penelitian ini adalah snowball sampling atau bola bergelinding. Dalam penelitian ini, nantinya informan kunci dari radio Suara Edukasi akan menunjuk informan lain yang mampu menjelaskan permasalahan yang akan diteliti ini. Pemilihan informan dengan teknik snowball sampling menghasilkan Sub Koordinator Pemanfaatan dan Pengendalian bagian dari Tim Leader (TL) penyiaran radio Suara Edukasi dan Penyiar atau Reporter radio Suara Edukasi. Selanjutnya adalah teknik analisis data yang digunakan dalam penelitian ini yaitu, melalui reduksi data, penyajian data dan penarikan kesimpulan.

\section{Hasil Penemuan dan Diskusi}

Siaran radio pendidikan dengan nama radio Suara Edukasi, telah diselenggarakan oleh Pusat Data dan Teknologi Informasi Kementerian Pendidikan dan Kebudayaan (Pusdatin) sejak bulan Januari 2009, berlokasi di Pusdatin Kemendikbud Jl. RE Martadinata KM 15,5 Ciputat, Tangerang Selatan, Banten. Radio Suara Edukasi diselenggarakan untuk menjadi siaran radio yang bisa dijadikan sebagai, media alternatif sumber belajar dalam rangka mencapai tujuan pendidikan Nasional. Suara Edukasi sebagai sebuah media massa radio, sudah semestinya mempunyai sebuah profil untuk sebuah identitas. Profil radio Suara Edukasi meliputi beberapa hal, diantaranya yaitu segmentasi, positioning, tagline, dan lain-lain. Radio Suara Edukasi mempunyai tagline yaitu "Akrab dan Mencerdaskan" terlihat dari penyajian materi program siarannya yang kreatif dan edukatif. Program-program siaran yang dimiliki oleh radio Suara Edukasi diantaranya yaitu Sapa Edu, Ayo Belajar SD, Kita Perlu Tahu, Info Edu, Ayo Belajar SMP, EKSAKTA, dan Ayo Belajar SMK.

Tabel 1. Hasil Wawancara

\begin{tabular}{llll}
\hline Narasumber & Nama \& Jabatan & Keterangan & \\
\hline Narasumber & Abdul Majid, S.Pd & Menjabat sejak tahun 2018 sampai \\
utama (1) & (Pengkaji Media Naskah & sekarang, dan telah bergabung dengan \\
& Radio atau Audio dan & Pusdatin sejak tahun 2004. Sebelum \\
& Sutradara Program & menjabat dalam unit Sub. Koordinator \\
& $\begin{array}{l}\text { Pembelajaran dalam Sub. } \\
\text { Koordinator Produksi Bahan, }\end{array}$ & berpengalaman menjabat sebagai produser \\
& Belajar berusia 48 tahun). & news TV Edukasi. \\
\hline Narasumber & Mira Maulia, S.Pd., M.Si. & Menjabat sejak tahun 2013 sampai \\
$(2)$ & (Team Leader (TL) penyiaran & sekarang. Sebelum menjabat sebagai Tim \\
& Radio Suara Edukasi dalam & Leader (TL) penyiaran Radio Suara \\
& Sub. Koordinator & Edukasi, beliau juga berpengalaman \\
& Pemanfaatan, berusia 38 38 menjabat di bagian perancangan dan \\
& tahun). & produksi konten pembelajaran di radio
\end{tabular}

\begin{tabular}{lll}
\hline Narasumber & Ade Agung Rachmadi. & Menjabat sebagai penyiar di radio Suara \\
(3) & Penyiar atau Reporter Radio & Edukasi sejak tahun 2012. Selain itu juga \\
& $\begin{array}{l}\text { Suara Edukasi, berusia 48 } \\
\text { tahun). }\end{array}$ & $\begin{array}{l}\text { selain menjabat sebagai penyiar, beliau } \\
\text { mempunyai pengalaman menjabat } \\
\text { menjadi penulis naskah video dan audio }\end{array}$ \\
\hline
\end{tabular}


Syifa Nurhaliza, Farid Rusdi: Strategi Komunikasi Program Radio Pendidikan Sebagai Media Sumber Pembelajaran dan Informasi

pendidikan di Radio Suara Edukasi dan Televisi

Edukasi.

\section{Sumber: Pengolah Data oleh Peneliti}

\section{Proses Strategi Komunikasi Pengelolaan Program Radio Suara Edukasi Di Tengah Pandemi COVID-19}

Strategi komunikasi yang dilakukan radio Suara Edukasi berdasarkan situasi pandemi Covid-19. Pada saat keadaan banyak sekolah yang menerapkan sitem belajar jarak jauh atau belajar dari rumah, sehingga radio dapat menjadi media yang dapat memenuhi kebutuhan informasi dan sarana pembelajaran. Fenomena tersebut dapat menjadi momentum agar radio Suara Edukasi dapat menarik lebih banyak lagi pendengar dengan program-program siaran yang berkualitas dan sesuai dengan kebutuhan masyarakat. Proses perencanaan tersebut, juga dilakukan secara cepat dan menyesuaikan situasi pada saat pandemi melalui rapat menggunakan aplikasi Zoom Meeting dengan pimpinan serta tim internal. Hasil dari rancangannya yaitu, melakukan analisis kebutuhan dengan mewawancarai guru PAUD sampai SMA, Menambah program siaran radio, mengubah jadwal siaran dan materi dalam setiap program siaran lebih intens mengenai materi pendidikan, serta adanyan penambahan hari siaran di akhir pekan yaitu hari Sabtu dan Minggu dan diisi oleh program siaran hiburan. Itulah proses dari perencanaan hasil rancangan strategi komunikasi yang dilakukan oleh radio Suara Edukasi pada saat situasi pandemi Covid-19.

Pada saat penerapan work from home, proses pengelolaan atau pelaksanaan siaran tetap dilakukan di studio dengan melakukan peraturan dari kantor yaitu melakukan sesuai dengan protokol kesehatan dan social distancing. Selain itu juga, radio Suara Edukasi menerapkan pembatasan karyawan kru siar yang berada di dalam studio yaitu hanya satu orang yang melakukan siaran. Namun pada saat awal pandemi kantor menerapkan WFH, penyiar melakukan siaran radio dari rumah dengan menggunakan device yang telah disediakan dari kantor. Pada saat awal pandemi narasumber tidak bisa datang langsung ke studio untuk melakukan siaran maka dari itu siaran dilakukan secara daring dengan melakukan siaran langsung menggunakan aplikasi sosial media Instagram dengan narasumber melalui akun instagram resmi @ suara.edukasi dan juga disiarkan on-air di studio melalui website radio Suara Edukasi. Meskipun dilakukan dengan daring pendengar dapat mendengarkan program siaran pada saluran radio Suara Edukasi.

Gambar 1. Aktivitas Pada Postingan Live Instagram Radio Suara Edukasi

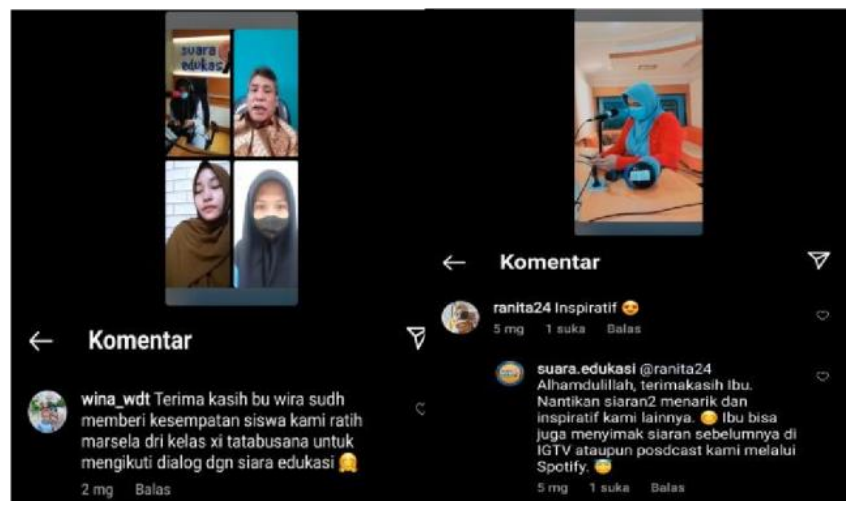

Sumber: Dokumentasi Pribadi 
Dapat dilihat dari aktivitas pada postingan live instagram radio Suara Edukasi, pengikut atau pendengar siaran langsung radio suara edukasi memberikan respon yang baik mengenai penggunaan live Instagram sebagai sarana siaran yang baru. Dengan menggunakan aplikasi sosial media Instagram, audiens dapat berinteraksi langsung antara penyiar dan narasumber melalui live chat pada saat live Instagram ataupun pada kolom komentar. Itulah proses pengelolaan atau pelaksanaan strategi yang telah direncanakan sebelumnya dan semua proses tersebut dapat dilakukan dengan baik.

Tidak terlalu banyak tantangan yang dihadapi oleh radio Suara Edukasi pada saat pandemi, namun tantangan- tantangan tersebut dapat diatasi dengan baik oleh radio Suara Edukasi. Beberapa tantangannya yaitu, pada saat penerapan bekerja dari rumah dengan daring, tim siar tidak ada di studio, hal tersebut dapat ditangani dengan oleh perusahaan dengan memfasilitasinya dengan perangkat yang diberikan kepada tim penyiar ketika bekerja dari rumah. Tantangan yang kedua adalah penyiar atau reporter yang dipindahkan dari program sebelumnya, harus dapat berdaptasi dan memperkaya wawasan dan pengetahuannya mengenai konten program baru, hal tersebut dapat diatasi dengan rapat rutin serta sosialisasi dan juga dengan bantuan para narasumber ahli dalam bidangnya yang diundang untuk mengisi acara siaran pada program radio Suara Edukasi. Itulah tantangan yang dihadapi oleh radio Suara Edukasi dalam melaksanakan strategi komunikasinya dalam mengelola program siarannya pada saat pandemi Covid-19.

Dalam proses evaluasi, radio Suara Edukasi melakukan evaluasi untuk mengoreksi efektifitas penggunaan strategi komunikasi yang telah dilakukan pada saat pandemi Covid-19 pada program siarannya. Proses evaluasi tersebut dilakukan seacara rutin, sesuai dengan alur pengembangan program dengan cara preview ahli, lalu dilakukan uji coba prototipe (kelompok kecil / lapangan) setelah itu finalisasi. Dapat dilihat dari ringkasan statistik radio Suara Edukasi dibawah ini, dari tahun 2017 sampai dengan tahun 2021 terjadi peningkatan pendengar streaming radio melalui kunjungan daftar website pada saat pandemi Covid-19 yaitu, pada tahun 2020 dan 2021.

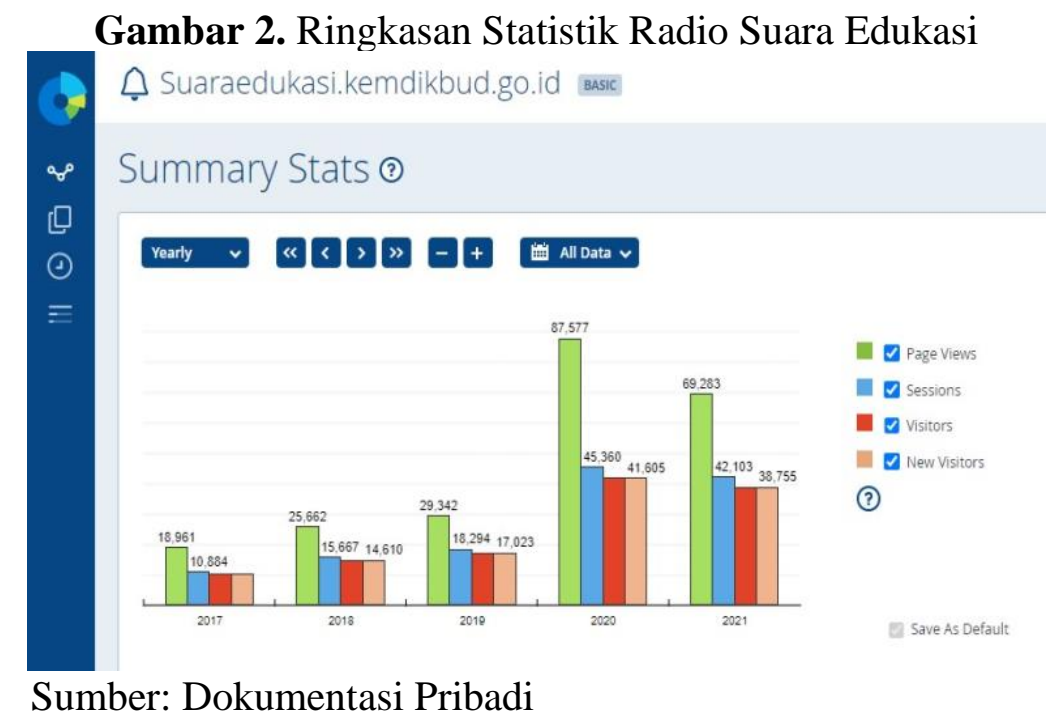

Peningkatan tersebut membuktikan bahwa strategi radio Suara Edukasi dalam memperbaharui dan menambah program siarannya, berdapak baik yaitu menarik lebih banyak perhatian pendengar. Dibandingkan pada saat sebelum pandemi, radio Suara Edukasi lebih dikenal oleh masyarakat pada saat pandemi Covid-19 dan dapat 
Syifa Nurhaliza, Farid Rusdi: Strategi Komunikasi Program Radio Pendidikan Sebagai Media Sumber Pembelajaran dan Informasi

menjangkau lebih banyak lagi pendengarnya. Strategi komunikasi dalam mempertahankan dan menarik pendengar ditengah pandemi Covid-19 melalui program siaran.

\section{Strategi Komunikasi Dalam Mempertahankan Dan Menarik Pendengar Ditengah Pandemi COVID-19 Melalui Program Siaran}

Strategi komunikasi yang dilakukan radio Suara Edukasi pada saat pandemi Covid-19 yaitu, melalui berbagai media informasi dan hiburan berbasis online, yaitu seperti Instagram dan Spotify. Radio Suara Edukasi juga menggunakan aplikasi aplikasi Spotify sebagai strategi komunikasi pada saat pandemi Covid-19. Pendistribusian konten radio lebih diperluas lagi melalui media sosial Youtube yang salah satunya adalah melalui podcast. Pendengar Radio Suara Edukasi dapat mendengarkan siaran program radio melalui podcast pada aplikasi Spotify dan dapat mengunduh podcast tersebut pada laman website resmi radio Suara Edukasi.

Gambar 3. Data Statistik Bulanan Spotify Radio Suara Edukasi 2021

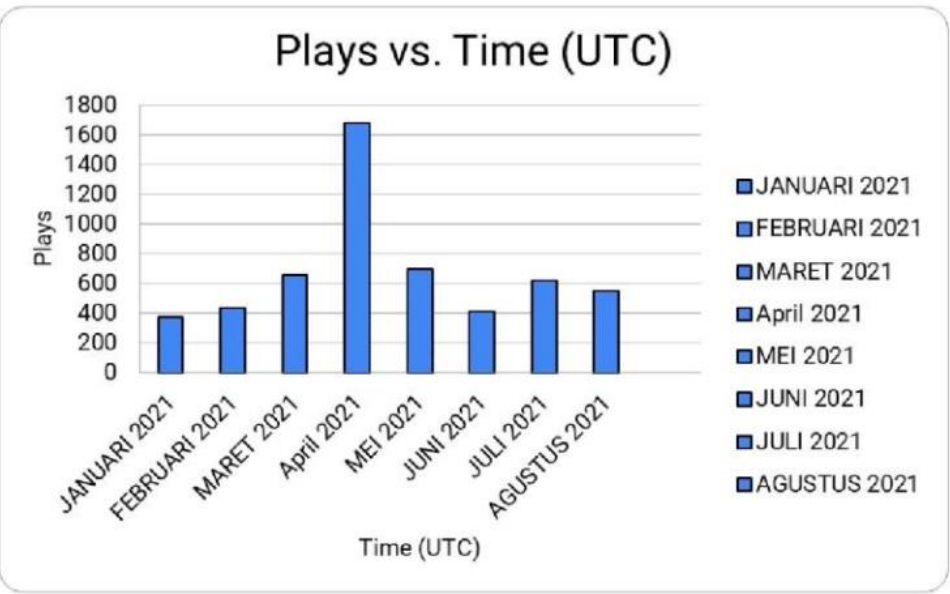

Sumber: Dokumentasi Pribadi

Pendengar radio Suara Edukasi pada saat ini sudah mengenal dan mulai menggunakan aplikasi Spotify untuk mendengarkan podcast radio Suara Edukasi. Dilihat dari statistik pada tahun 2021 pendengar podcast radio Suara Edukasi stabil, pada setiap bulannya dan terjadi peningkatan yang cukup besar pada bulan april 2021 . Radio Suara Edukasi juga menjadi media partner program Belajar dari Rumah di TV Edukasi Kemendikbud yang bekerja sama dengan stasiun TVRI, sebagai strategi komunikasi pada saat pandemi Covid-19. Itulah beberapa media yang digunakan oleh radio Suara Edukasi sebagai strategi komunikasi dalam memberikan informasi pembelajaran, agar dapat mempertahankan dan menarik pendengar di tengah pandemi Covid-19 melalui program siaran.

Hasil yang didapatkan oleh peneliti dari proses wawancara, observasi, dan juga dokumentasi yang kemudian dianalisis menggunakan teori yang relevan dengan data yang sudah dikumpulkan di lapangan. Tahap ini data yang sudah dianalisis kemudian akan memunculkan sebuah temuan, lalu dikonfirmasikan dengan perspektif teori yang digunakan dalam penelitian ini, apakah teori sesuai atau tidak. Teori tahapan strategi komunikasi yang dipaparkan oleh Phill Jones, dapat dilakukan oleh organisasi untuk mencapai tujuannya. Terdapat lima tahapan strategi komunikasi yang dipaparkan oleh Phill Jones untuk organisasi yang ingin mencapai tujuannya maka, tahap yang harus 
digunakan dalam strategi komunikasinya yaitu yang sesuai dengan situasi dan kondisi organisasi tersebut serta melewati lima tahap yaitu, tahap analisis dan perencanaan strategis, desain strategi dan implemtasi perencanaan, pelaksanaan strategi, tindak lanjut dan komitmen, yang terakhir adalah menambahkan strategi dan pelacakan hasil. Lima tahapan tersebut harus dilakukan secara berurutan, sehingga hasil yang didapatkan akan maksimal.

Itulah hasil temuan peneliti, yang kemudian peneliti konfirmasikan kedalam teori tahapan strategi komunikasi Phill Jones yaitu, melakukan perencanaan ulang strategi komunikasi sesuai dengan situsi dan kondisi, pemanfaatan media sosial Instagram sebagai alat komunikasi efektif saat siaran pada masa pandemi Covid-19, media baru sebagai strategi komunikasi untuk mempertahankan dan menarik pendengar ditengah pandemi Covid-19 melalui program siaran.

\section{Simpulan}

Radio Suara Edukasi AM, sebagai media sumber pembelajaran dan informasi yang dibutuhkan oleh masyarakat khususnya pelajar dan guru atau tenaga pendidik, mempunyai strategi komunikasi pada program siarannya. Strategi komunikasi radio Suara Edukasi pada saat pandemi Covid-19, dilakukan dari mulai proses perencanaan melalui rapat menggunakan aplikasi Zoom. Rapat dilakukan dengan tim internal radio Suara Edukasi untuk merancang design kegiatan siaran dan efisiensi selama pandemi Covid-19. Dengan menambah program siaran, mengubah waktu siaran pada programnya serta menggunakan media sosial Instagram sebagai strategi komunikasi yang baru ketika siaran bersama narasumber. Pada saat proses pelaksanaan atau pengelolaan radio Suara Edukasi, walaupun ada beberapa kendala yang harus dihadapi pada saat pandemi Covid-19, namun pengelolaan radio berjalan dengan baik sesuai dengan design atau rencana yang telah dibuat sebelumnnya.

Selanjutnya pada saat proses evaluasi, radio Suara Edukasi melakukan evaluasi secara berkala yang dilakukan oleh 2 ahli media dari Pusdatin dan oleh ahli materi seperti dari guru atau dosen. Beberapa tantangan yang dihadapi oleh radio Suara Edukasi dapat diatasi dengan baik dan tantangan dan evaluasi tersebut dapat membuat radio Suara Edukasi semakin kreatif, informatif dan adaptif pada saat pandemi Covid19.

Strategi komunikasi yang dilakukan radio Suara Edukasi dalam mempertahankan dan menarik pendengarnya pada saat pandemi Covid-19 yaitu, melalui berbagai media informasi dan hiburan berbasis online, yaitu seperti Instagram dan podcast di aplikasi Spotify. Radio Suara Edukasi semakin dikenal oleh masyarakat, dengan penggunaan media sosial tersebut radio Suara Edukasi dapat menjangkau atau beradaptasi dengan pendengar radio Suara Edukasi di kalangan remaja. Selain itu Radio Suara Edukasi menjadi media partner program Belajar dari Rumah di TV Edukasi Kemendikbud yang bekerja sama dengan stasiun TVRI, sebagai strategi komunikasi pada saat pandemi Covid-19. Berbagai cara yang dilakukan oleh radio ini agar radio Suara Edukasi dapat mempertahankan pendengarnya dan dapat lebih dikenal lagi oleh masyarakat. Suara Edukasi melakukan tahapan-tahapan strategi komunikasi dengan baik, demi tercapainya sebuah tujuan organisasi. Pada saat ini, strategi komunikasi selama pandemi yang sudah ditetapkan dan disempurnakan akan terus digunakan dan dikembangkan. 
Syifa Nurhaliza, Farid Rusdi: Strategi Komunikasi Program Radio Pendidikan Sebagai Media Sumber Pembelajaran dan Informasi

\section{Ucapan Terima Kasih}

Peneliti mengucapkan terima kasih kepada Fakultas Ilmu Komunikasi Universitas Tarumanagara, narasumber, serta semua pihak yang turut membantu peneliti sehingga penelitian ini dapat diselesaikan.

\section{Daftar Pustaka}

Amiliani, Y., Pawito, \& Soedarmo. (2020). Pemanfaatan Peran Radio Ditengah Pandemi COVID-19 Di Surakarta. Prosiding Seminar Nasional Unimus.

Creswell, J. W. (2013). Qualitative Inquiry \& Research Design Choosing among Five Approaches (3rd ed.). Thousand Oaks, CA SAGE

Djamal Hidajanto, F., \& Andi. (17 C.E.). Dasar-dasar Penyiaran: Sejarah, Organisasi, Operasional, dan Regulasi (2nd ed.). Prenada Media.

Dominica, L., Fauziah, L., \& Pramesti, A. I. (2021). Proses Pendirian Radio Komunitas Suara Edukasi oleh Universitas Muhammadiyah Yogyakarta di Kulon Progo di Masa Pandemi Covid-19 . Jurnal Audiens, 2(2), 261-272.

Effendy, O. U., \& Surjaman, T. (2011). Ilmu komunikasi teori dan praktek. (1st ed.). Remaja Rosdakarya.

Jayani Dwi Hadya. (2021). 78\% Sekolah di Indonesia Masih Belajar Jarak Jauh | Databoks.

Katadata.

https://databoks.katadata.co.id/datapublish/2021/04/01/78-sekolahdiindonesia-masih-belajar-jarak-jauh

Phil Jones. (2012). Communicating Strategy. Ashgate Publishing Limited. 